\title{
Amelogenezis imperfekta hastasının oral rehabilitasyonu: Olgu sunumu
}

\author{
Elif Sadık ${ }^{1}$, Ersan Çelik², Ceren Gökmenoğlư ${ }^{3}$, Elif Bahar Çakıc ${ }^{4}$
}

Selcuk Dent J, 2016; 3: 82-86

Başvuru Tarihi: 18 Şubat 2016 Yayına Kabul 16 Haziran 2016

\begin{abstract}
öz
Amelogenezis imperfekta hastasının oral rehabilitasyonu: Olgu sunumu

Amelogenezis imperfekta (Ai) süt ve daimi dentisyonu etkileyen herediter bir mine gelişim anomalisidir. Dişlerde mine hipoplazisi, hipomaturasyonu veya hipokalsifikasyonu ile karakterize olan bu anomalinin tedavisinde estetik ve fonksiyonun kazandırıması ile birlikte psikolojik olarak da olumlu sonuçlarla hasta memnuniyetinin sağlanması amaçlanmaktadır. Bu olgu raporunda; kliniğimize başvuran hipomature tip Ai'li genç erkek hastanın oral rehabilitasyonu sunulmaktadır.
\end{abstract}

\section{ANAHTAR KELIMELER}

Amelogenezis imperfekta, Dental estetik, hipomature tip

Amelogenezis imperfekta (Ai) süt ve daimi dentisyonu etkileyen herediter bir mine gelişim anomalisidir (Gadhia ve ark. 2012). Literatürde bu anomali için çok sayıda sınıflama bulunmaktadır (Aldred ve ark. 2003). Genetik ve klinik özelliklere göre yapılan bu sınıflamaların en çok kabul edileni Witkop'un (1988) sınıflamasıdır. Bu sınıflamaya göre Ai hipoplastik, hipomature, hipokalsifiye ve taurodontizm ile birlikte gözlenen hipomature-hipoplastik olmak üzere dört ana gruba, bu dört ana grup ise klinik, radyolojik, histolojik ve genetik özelliklerine göre 15 alt gruba ayrılır. En sık görülen hipoplastik tipte, minenin yapısı normal ancak kalınlığı azdır. Hipoplazi alanlarında çukurlar ve oluklar gözlenir. Radyolojik olarak mine normal opasitede izlenir ancak çok incedir. Hipokalsifiye tipte mine normal kalınlıkta oluşmuş fakat çok düşük mineralizasyona sahiptir, yumuşaktır ve kolayca dentin yüzeyinden ayrılabilir. Dişin sürmesini takiben hızla aşınır. Düşük mineral içeriğinden dolayı radyolojik olarak minenin opasitesi azalmıştır. Hipomature tipte organik matriks oluşumu

\section{ABSTRACT}

Oral rehabilitation of the patient with amelogenesis imperfecta: A case report

Amelogenesis imperfecta (Al), is a hereditary disorder affecting the enamel of primary and permenant teeth. It can be characterized by enamel hypoplasia, hypomaturation or hypocalcification of the teeth. In treatment of this anomaly, main goal is to achieve esthetic and function as well as patient satisfaction with positive treatment outcomes. In this case report, oral rehabilitation of a young male patient referred to our clinic diagnosed with the hypomaturation type of Al was presented.

\section{KEYWORDS}

Amelogenesis imperfecta,dental esthetic, hypomaturation type

normal ancak mine kristal yapısının maturasyonu defektlidir. Normal kalınlıktaki mine lekeli opak beyaz, sarı-kahverengi veya kırmızı-kahverengi renkte ve normale oranla biraz daha yumuşaktır. Radyogramda mine-dentin ayırımını yapmak zordur (Gadhia ve ark. 2012, Gisler ve ark. 2010, Mehta ve ark. 2013). Taurodontizm ile birlikte gözlenen hipomature-hipoplastik tipte ise taurodont dişlerde hipoplastik ve hipomature tip Ai özellikleri karışık olarak izlenir (Gadhia ve ark. 2012). Bu güne kadar yapılan çalışmalarda dokuz farklı gen (AMELX, CNNM4, DLX3, ENAM, FAM20A, FAM83H, KLK4, MMP20 ve WDR72) üzerinde oluşan mutasyonlar ya da gen ekspresyonundaki değişikliklerin Ai'ye neden olduğu bildirilmiştir (Zhang ve ark. 2015, Gadhia ve ark. 2012, Wright ve ark. 2009a, Lee ve ark. 2008, Wright ve ark. 2009b, Simmer ve ark. 2009, Hu ve ark. 2008). Bu genlerden dört tanesi (AMELX, ENAM, MMP20, KLK4) mine matriks proteinlerini kodlarken, diğer genlerin amelogenezis sırasındaki fonksiyonları tam olarak açıklanamamıştır (Zhang ve ark. 2015).

\footnotetext{
1 Ordu Üniversitesi Diş Hekimliği Fakültesi Ağız Diş ve Çene Radyolojisi AD, Ordu

2 Ordu Üniversitesi Diș Hekimliği Fakültesi Protetik Diş Tedavisi AD, Ordu

${ }^{3}$ Ordu Üniversitesi Diş Hekimliği Fakültesi Periodontoloji AD, Ordu

${ }^{4}$ Ordu Üniversitesi Diş Hekimliği Fakültesi Endodonti AD, Ordu
} 
Ai nadir görülen bir anomali olmakla birlikte görülme sıklığı çalışılan popülasyona bağlı olarak farklılık göstermektedir. Literatürde Al görülme sıklığı Türkiye'de \%0.43 (Altug-Atac ve Erdem 2007), İsveç'te \%0.14 (Bäckman ve Holm 1986), İsrail'de \%0.01 (Chosack ve ark. 1979 ) olarak bildirilmiştir.

Ai hastalarında diş hassasiyeti, dikey boyut kaybı, yetersiz dental estetik gibi durumların yanı sıra; sürme anomalileri, açık kapanış, konjenital diş eksikliği, kronkök rezorpsiyonu, kök malformasyonları, hipersementoz, pulpa kalsifikasyonu gibi anomalilere de rastlanmaktadır (Seow 1993, Alachioti ve ark. 2014, Poulsen ve ark. 2008, Gisler ve ark. 2010). Ayrica bu hastalarda çürüğe yatkınlık, yoğun diştaşı birikimi ve gingival hiperplazi gibi klinik bulgular görülebilmektedir (Chen ve ark. 2013).

Günümüzde Ai hastalarının tedavisi disiplinlerin ortak çalışmasını gerektirir. Bu hastaların tedavisinde estetik ve fonksiyonun kazandırılması ile birlikte psikolojik olarak da olumlu sonuçlarla hasta memnuniyetinin sağlanması amaçlanmaktadır. Bu olgu sunumunda kliniğimize başvuran Al'li bir hastanın disiplinler arası oral rehabilitasyonu anlatılmıştır.

\section{OLGU}

Yirmi yaşında erkek hasta, alt ve üst dişlerindeki sarıkahverengi lekeler ve iyi olmayan estetik görünümü şikayeti ile kliniğimize başvurdu. Alınan medikal anamnezinde herhangi bir sistemik hastalığının olmadığı, sürekli kullandığı bir ilaç bulunmadığı öğrenildi. Yapılan ağız dışı muayenesinde herhangi bir anomali tespit edilmedi. Ağız içi muayenesinde yumuşak dokulara yönelik herhangi bir patolojiye rastlanmadı. Hastanın periodontal sağlığı ve oral hijyeni iyi durumdaydı. Ağızda mevcut tüm dişlerin mine yüzeyinde sarı-kahverengi lekeler olduğu gözlendi (Resim 1).

Radyolojik muayene için hastadan ortopantomografi (Kodak 8000C Dijital Panoramik ve Sefalometrik Sistem; Carestream Health, Inc. Rochester, NY) alındı (Resim 2).

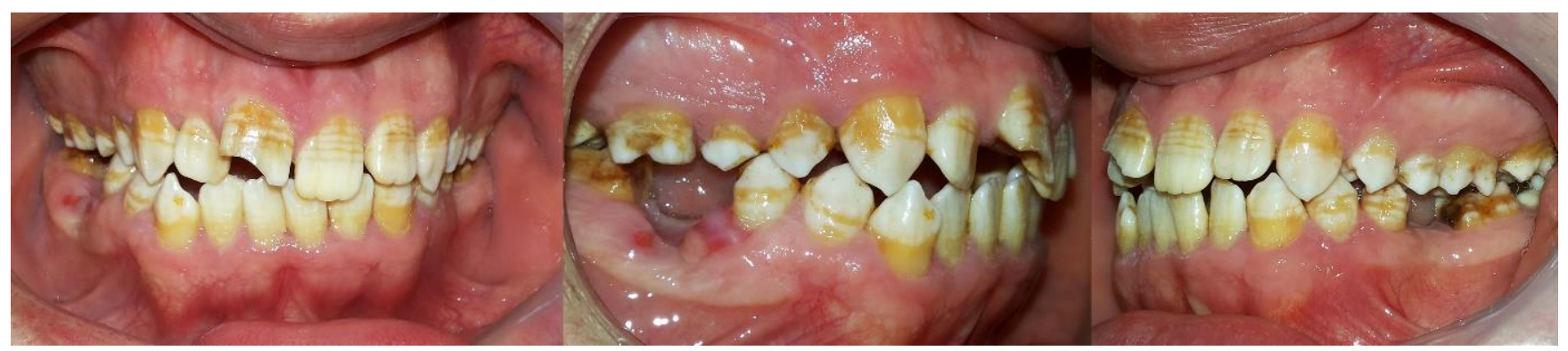

Resim 1.

Tedavi öncesi ağız içi görünüm

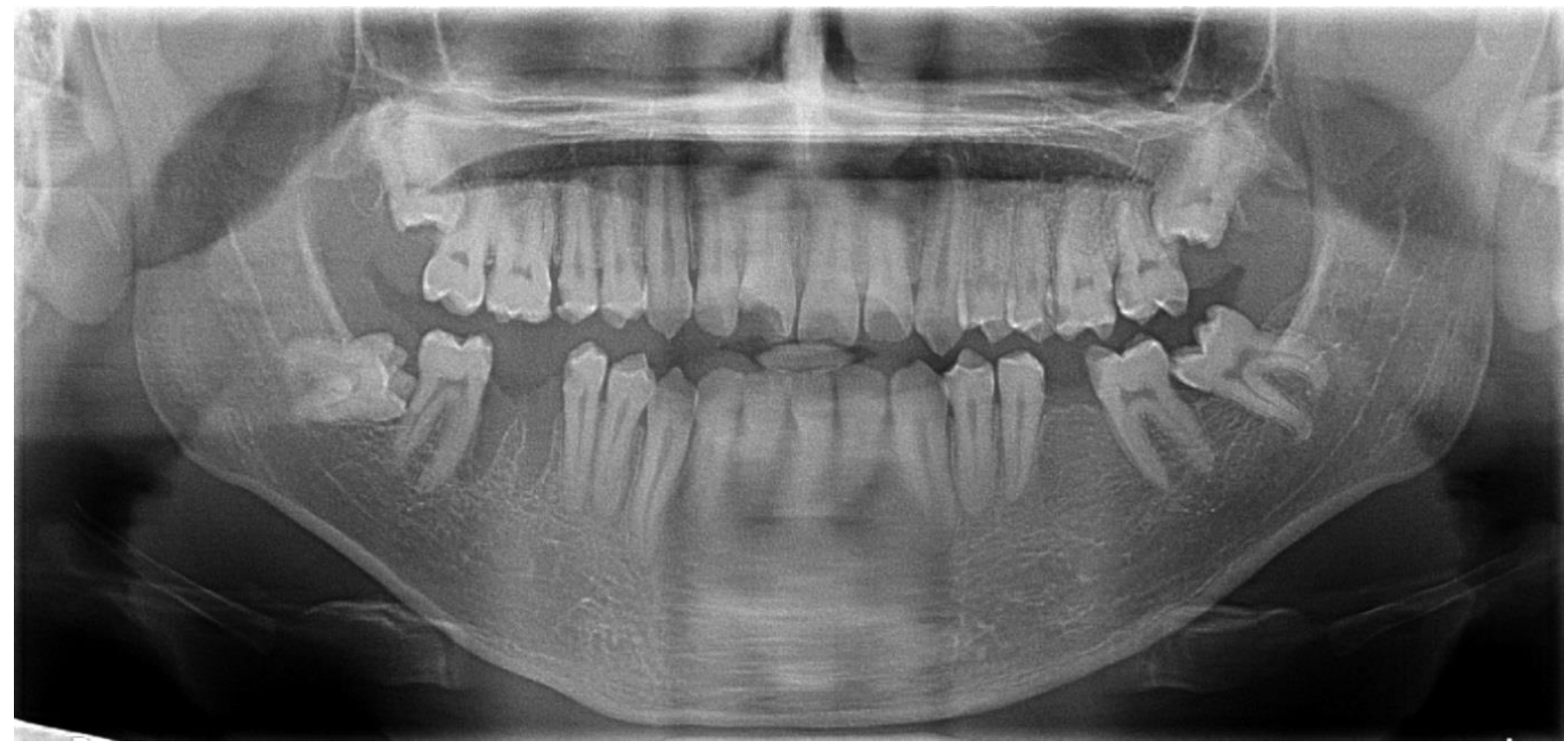

Resim 2.

Tedavi öncesi ortopantomogram 
Klinik ve radyolojik muayenede hastanın 36 ve 46 numaralı dişlerinin eksik, 15, 16, 24, 25, 26, 27, 35, 37, 45, 47 numaralı dişlerinde de aproksimal çürükler olduğu tespit edildi. 18, 28 ve 48 nolu dişler tam gömülü, 38 nolu diş ise yarı gömülü idi. Andreasen (1981) sınıflamasına göre komplike olmayan kron kırığı olan vestibulopozisyondaki 11 numaralı dişe elektrikli pulpa testi (Parkell Electronics Division, Farmingdale, NY) yapıldı ve ilgili dişin vital olduğu belirlendi. Radyografik incelemeyle birlikte diş kronları normal boyutta, mine tabakası ise ince fakat normal opasitede gözlendi. Hastadan alınan anamnezde erkek kardeşinin dişlerinde de benzer görünümün olduğu ve aynı şikayetle dişlerine porselen kron yapıldığı öğrenildi. Klinik ve radyografik bulgularla hastaya hipomature tip Ai tanısı konuldu. Multidisipliner yaklaşımla tedavi planlaması yapıldı. Hasta farklı protetik tedavi seçenekleri hakkında bilgilendirildi, alt-üst tüm ağız sabit restorasyon yapılmasına karar verildi ve hastadan bilgilendirilmiş onam formu alındı.

Tedavi aşamasında 48 ve 38 nolu dişler çekildi. Sağ ve sol üst çene premolar ve molar bölgelerindeki dişeti seviyeleri anterior dişleri ile uyumlu değildi. Yapılacak protetik uygulamanın estetiğini arttırmak amacıyla, ilgili dişeti bölgelerinde yapışık dişeti bandının da yeterli olması nedeniyle bilateral olarak gingivektomi yapılmasına karar verildi. Dişetleri infiltratif anestezi ile uyuşturuldu. Periodontal sond yardımıyla eksize edilecek dişeti seviyesinin apikal sınırları işaretlendi. Ardından 15 numaralı bistüri işaretlenen noktaların apikalinden kuronale doğru diş ile 45'lik açı yapacak şekilde yönlendirilerek dişeti dokusu eksize edildi. Dişetlerinin bilateral olarak simetrik olmasına ve anterior dişler ile uyumunun sağlanmasına dikkat edildi. Sekonder iyileşmeye bırakılan yara yüzeyleri periodontal pat ile kapatıldı. 11 numaralı dişe protetik amaçla tek seans kök kanal tedavisi planlandı. İlgili dişe anestezi yapıldıktan sonra rubber dam uygulanarak izolasyon sağlandı. Giriş kavitesi hazırlandıktan sonra 10 numaralı K tipi kanal eğesi kullanılarak ROOT ZX mini apeks bulucu (Morita, Kyoto, Japonya) ile çalışma boyu belirlendi. Alınan radyografi ile çalışma boyu doğrulandıktan sonra Reciproc eğe sistemine (VDW, Münih, Almanya) ait R50 numaralı eğe ile kemomekanik şekillendirme tamamlandı. İrigasyon solüsyonu olarak \%2,5'lik sodyum hipoklorit (Wizard, Rehber Kimyasal, İstanbul, Türkiye) kullanıldı. Kanal paper pointle (Pearl Dent, Gyonggi-Do, Kore) kurulandıktan sonra R50 numaralı gutta perka (VDW, Münih, Almanya) ve 2 Seal (VDW, Münih, Almanya) kanal patı ile kanal tedavisi tek seansta tamamlandı. Kompozit dolgu (Filtek; 3M ESPE, St.Paul, ABD) ile üst restorasyon yapıldı. Aproksimal çürük tespit edilen dişlerin tümüne uygun kaviteler hazırlandıktan sonra kompozit dolgu ile restorasyonları tamamlandı.
Preprotetik tedavilerin ardından alt ve üst çeneden aljinat ölçü maddesi (Cavex Impressional; Cavex, Hollanda) ile ölçü alınarak sert alçıdan (Elite Rock; Zhermack, Rovigo, Italya) diagnostik modeller elde edildi. Artikülatöre alınan modeller ve hastada yapılan analizler sonucunda oklüzal dikey boyutta bir azalma olmadığı tespit edildi. Öngörülen tedavi sonuçlarını hastaya anlatabilmek için wax-up modeller hazırlanıp, hastanın da onayını aldıktan sonra üst çene anterior bölgeye metal desteksiz Y-TZP (LavaFrame, 3M ESPE, St.Paul, ABD) kronların, kalan dişler için de metal destekli porselen restorasyonların yapımına karar verildi. Gerekli diş preparasyonlarının ardından bilinen yöntemlerle restorasyonlar tamamlanarak metal desteksiz restorasyonlar adeziv rezin simanla (Panavia F 2.0; Kuraray, Osaka, Japonya) diğerleri de polikarboksilat simanla (Adhesor Carbofine; Spofa Dental, Macaristan) simante edildi (Resim 3, Resim 4).

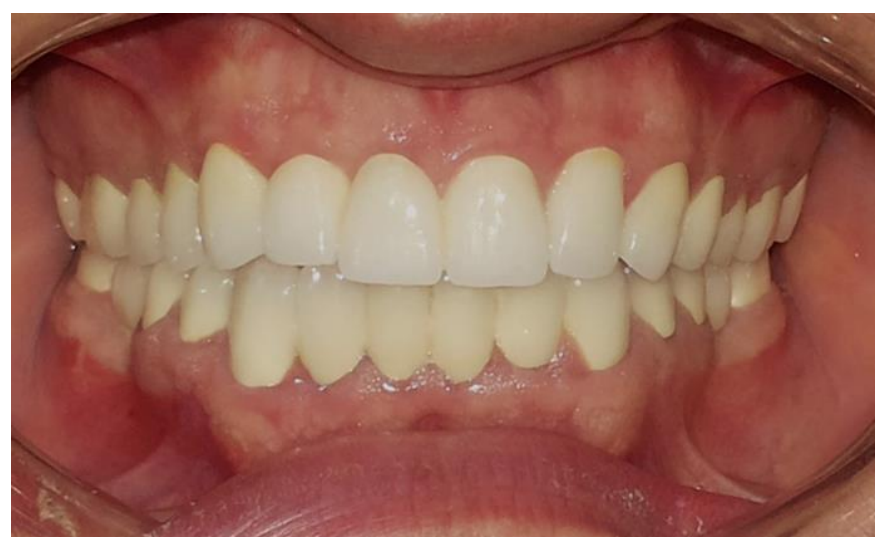

Resim 3.

Tedavi sonrası ağız içi görünüm

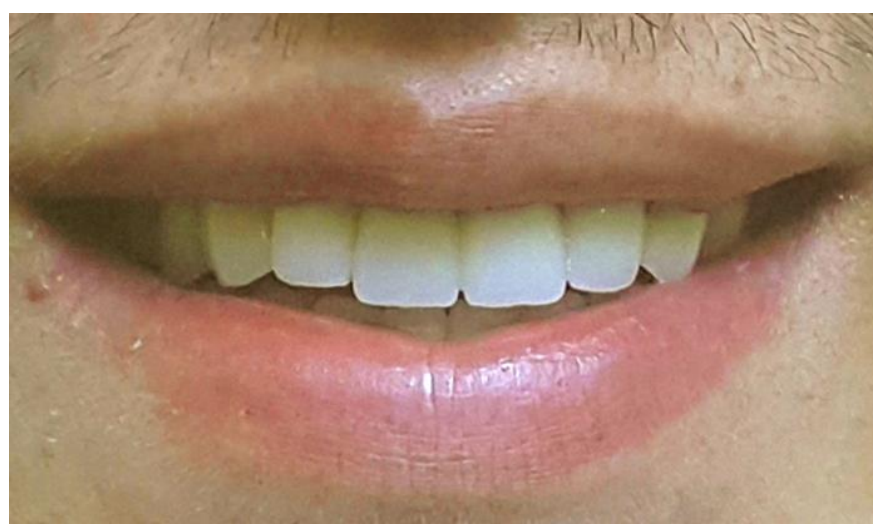

Resim 4.

Tedavi sonrası ağız dışı görünüm

Estetik ve fonksiyonel açıdan memnun edici sonuç elde edilip hasta oral hijyen konusunda motive edilerek kontrol seansları için randevu verildi. 


\section{TARTIŞMA}

Ai olgularında dişlerin görünümü ve hassasiyet, renklenme, pürüzlülük gibi mine ile ilişkili problemler hastaları psikolojik, estetik ve fonksiyonel olarak etkilemektedir. Bu hastaların teşhisi çoğunlukla klinik ve radyografik bulgulara dayanarak fenotipe göre konur. İdeal tedavi planı hastanın yaşı, sosyoekonomik durumu, dental ve periodontal dokuların sağlığı, anomalinin tipi ve şiddeti, hastanın beklentisi gibi birçok faktörden etkilenmektedir (Öztürk ve ark. 2004, Demirci ve ark. 2015). Dental materyaller ve tekniklerdeki gelişmelerle birlikte bu hastaların tedavisinde birçok farklı yöntem kullanılabilmektedir. Yapılan çalışmalarda Ai hastalarının cam iyonomer restorasyonlar, kompozit restorasyonlar, paslanmaz çelik kronlar, porselen kronlar, onley uygulamaları ve overdenture uygulamaları ile tedavi edildiği bildirilmiştir (Chen ve ark. 2013, Sengun ve Özer 2002, Yamaguti ve ark. 2006, Akin ve ark. 2007). Hipoplastik Al'de mine, bonding uygulamaları için genellikle yeterlidir. $\mathrm{Bu}$ hastalarda kron morfolojisinin iyileştirilmesi ve renklenmenin başarılı bir şekilde tedavisi için kompozit restorasyonlar düşünülebilir. Ancak dikey boyut kaybı oluşan hastalarda ideal oklüzyonu sağlamak için kron restorasyonlar, onley uygulamaları ve overdenture protezler önerilmektedir (Chen ve ark. 2013, Demirci ve ark. 2015). Hipokalsifiye Ai hastalarında mine, bonding uygulamaları için yetersizdir. Cam iyonomer siman ve kompozit rezin restorasyonlar bu vakalarda başlangıçta başarıı olabilir, ancak uzun dönemde hipokalsifiye minede oluşabilecek olan kırıklar marjinlerde defektlere ve restorasyonlarda kırılmalara neden olabilir. Şiddetli mine hasarının olduğu hipokalsifiye Ai vakalarında full-kron restorasyonlar tavsiye edilmektedir (Chen ve ark. 2013, Demirci ve ark. 2015). Hipomature Al'de ise mine, aşırı organik madde içerir. Mine hasarının şiddetli olmadığı vakalarda geleneksel yaklaşımlar ile restore edilebilir. Ancak şiddetli vakalarda defektli mine tamamen uzaklaştırımalı ve protetik yaklaşım tercih edilmelidir (Chen ve ark. 2013, Demirci ve ark. 2015). Olgumuz hipomature tip Ai olduğundan ve dişlerde yaygın defektler bulunduğundan dolayı full kron restorasyon ile tedavi düşünülmüştür.

Al'li hastaların tedavisi sadece estetik ve fonksiyonel problemlerin tedavi edilmesi yönünden değil, hastanın sosyo-psikolojik durumunun olumlu yönde etkilenmesi bakımından da gereklidir. Bu hastalarda zamanla doku yıkımının artması ve erken diş kayıplarının önlenmesi açısından tedaviye mümkün olduğunca erken yaşlarda başlamak önemlidir. 


\section{KAYNAKLAR}

Akin H, Tasveren S, Yeler DY, 2007. Interdisciplinary approach to treating a patient with amelogenesis imperfecta: A clinical report. J Esthet Restor Dent, 19, 131-135.

Alachioti XS, Dimopoulou E, Vlasakidou A, Athanasiou $A E, 2014$. Amelogenesis imperfecta and anterior open bite: Etiological, classification, clinical and management interrelationships. J Orthod Sci, 3, 1-6.

Aldred MJ, Savarirayan R, Crawford PJ, 2003. Amelogenesis imperfecta: a classification and catalogue for the 21st century. Oral Dis, 9,19-23.

Altug-Atac AT, Erdem D, 2007. Prevalence and distribution of dental anomalies in orthodontic patients. Am J Orthod Dentofacial Orthop, 131, 510514.

Andreasen J, 1981. Traumatic injuries of the teeth 2rd ed, Philadelphia: WB. Saunders Co.

Bäckman B, Holm AK, 1986. Amelogenesis imperfecta: prevalence and incidence in a northern Swedish county. Community Dent Oral Epidemiol, 14, 43-47.

Chen CF, Hu JCC, Bresciani E, Peters MC, Estrella MR, 2013. Treatment considerations for patient with Amelogenesis Imperfecta: a review. Braz Dent Sci Braz Dent Sci, 16, 7-18.

Chosack A, Eidelman E, Wisotski I, Cohen T, 1979. Amelogenesis imperfecta among Israeli Jews and the description of a new type of local hypoplastic autosomal recessive amelogenesis imperfecta. Oral Surg Oral Med Oral Pathol, 47, 148-156.

Demirci F, Tanik A, Güven S, 2015. Amelogenezis Imperfekta: Sınıflama, Teşhis ve Tedavi (Derleme). Atatürk Üniversitesi Diş Hekimliği Fakültesi Dergisi, 12, 149-155.

Gadhia K, McDonald S, Arkutu N, Malik K, 2012. Amelogenesis imperfecta: an introduction. Br Dent $\mathrm{J}$, 212, 377-379.

Gisler V, Enkling N, Zix J, Kim K, Kellerhoff NM, Mericske-Stern R, 2010. A multidisciplinary approach to the functional and esthetic rehabilitation of amelogenesis imperfecta and open bite deformity: a case report. J Esthet Restor Dent, 22, 282-293.

$\mathrm{Hu}$ JC, Hu Y, Smith CE, McKee MD, Wright JT, Yamakoshi Y, Papagerakis P, Hunter GK, Feng JQ, Yamakoshi F, Simmer JP, 2008. Enamel defects and ameloblast-specific expression in Enam knockout/lacz knock-in mice. J Biol Chem, 283, 1085810871.

Lee SK, Hu JC, Bartlett JD, Lee KE, Lin BP, Simmer JP, Kim JW, 2008. Mutational spectrum of FAM83H: the C-terminal portion is required for tooth enamel calcification. Hum Mutat, 29, E95-E99.
Mehta DN, Shah J, Thakkar B, 2013. Amelogenesis imperfecta: Four case reports. J Nat Sci Biol Med, 4, $462-465$.

Ozturk N, Sari Z, Ozturk B, 2004. An interdisciplinary approach for restoring function and esthetics in a patient with amelogenesis imperfecta and malocclusion: a clinical report. J Prosthet Dent, 92, 112-115.

Poulsen S, Gjørup H, Haubek D, Haukali G, Hintze H, Løvschall H, Errboe M, 2008. Amelogenesis imperfecta a systematic literature review of associated dental and oro-facial abnormalities and their impact on patients. Acta Odontol Scand, 66, 193-199.

Sengun A, Ozer F, 2002. Restoring function and esthetics in a patient with amelogenesis imperfecta: a case report. Quintessence Int, 33, 199-204.

Seow WK, 1993. Clinical diagnosis and management strategies of amelogenesis imperfecta variants. Pediatr Dent, 15, 384-393.

Simmer JP, Hu Y, Lertlam R, Yamakoshi Y, Hu JC, 2009. Hypomaturation enamel defects in Klk4 knockout/LacZ knockin mice. J Biol Chem, 284, 19110-19121.

Witkop CJ Jr, 1988. Amelogenesis imperfecta, dentinogenesis imperfecta and dentin dysplasia revisited: problems in classification. J Oral Pathol, 17, 547-553.

Wright JT, Hart TC, Hart PS, Simmons D, Suggs C, Daley B, Simmer J, Hu J, Bartlett JD, Li Y, Yuan ZA, Seow WK, Gibson CW, 2009a. Human and mouse enamel phenotypes resulting from mutation or altered expression of AMEL, ENAM, MMP20 and KLK4. Cells Tissues Organs, 189, 224-229.

Wright JT, Frazier-Bowers S, Simmons D, Alexander K, Crawford P, Han ST, Hart PS, Hart TC, 2009b. Phenotypic variation in FAM83H-associated amelogenesis imperfecta. J Dent Res, 88, 356-360.

Yamaguti PM, Acevedo AC, de Paula LM, 2006. Rehabilitation of an adolescent with autosomal dominant amelogenesis imperfecta: case report. Oper Dent, 31, 266-272.

Zhang C, Song Y, Bian Z, 2015. Ultrastructural analysis of the teeth affected by amelogenesis imperfecta resulting from $\mathrm{FAM} 83 \mathrm{H}$ mutations and review of the literature. Oral Surg Oral Med Oral Pathol Oral Radiol, 119, e69-e76.

\section{Yazışma Adresi:}

\section{Yrd.Doç.Dr. Elif SADIK}

Ordu Üniversitesi

Diş Hekimliği Fakültesi

Ağız, Diş ve Çene Radyolojisi Anabilim Dalı

52100 Altınordu,Ordu

E-mail: elifsadik@odu.edu.tr 